\title{
A PREFERÊNCIA PELA LIQUIDEZ E O COMPORTAMENTO DOS BANCOS NA OFERTA DE CRÉDITO EM REGIÕES PERIFÉRICAS: UM ESTUDO PARA O ESTADO DO PARÁ
}

Nathalia Wanzeler Lemos ${ }^{1}$

\section{INTRODUÇÃO}

Camila Vogt ${ }^{2}$

$\mathrm{Na}$ perspectiva pós-keynesiana, bancos são vistos como uma firma que possui a capacidade de criar crédito através da criação de moeda bancária. Ou seja, a partir da escolha entre liquidez e rentabilidade ocorre uma expansão ou contração da oferta de moeda, que gera uma expansão ou contração da oferta de crédito bancário. Empresários de bancos procuram ativamente construir suas fortunas ajustando seus ativos e passivos para aproveitar as oportunidades de lucro. Com isso, eles tomam suas decisões de portfólio levando em consideração as suas expectativas, o que delimita a sua preferência em manter ativos líquidos.

Tendo como foco a preferência pela liquidez, vale ressaltar que ela está intimamente relacionada à taxa de juros e concomitante a isso, também é estabelecida uma relação da moeda com a taxa de juros. A moeda representa os bens que não possuem rendimento e nem custo de manutenção significante, mas possuem alto prêmio de liquidez (KEYNES, 1936). Dessa forma, abrir mão da moeda para obter títulos representa abrir mão de uma maior liquidez, que é recompensada pelo preço oferecido, isto é, pelos juros pagos aos títulos.

Diante da incerteza quanto ao futuro, os bancos preferem aplicações mais líquidas e, consequentemente, menos rentáveis, a fim de evitar perdas. De acordo com Paula (2006), quando as expectativas dos bancos são positivas, eles preferirão uma menor liquidez e maior rentabilidade, ou seja, uma maior ascensão a riscos, o que gera um aumento de adiamentos e ativos de maior risco na carteira do banco, como os empréstimos de longo prazo. Essas ações proporcionam o aumento da oferta de crédito aos clientes, sendo que, quando as expectativas são pessimistas ocorre o processo contrário, destacando a contração da oferta de crédito

Esse processo de abrir mão da liquidez está intimamente ligado às incertezas e confiança do banco na região inserida, ou seja, em áreas menos desenvolvidas é possível observar uma maior instabilidade, e consequentemente, a incerteza também é maior, o que leva a uma maior preferência pela liquidez dos agentes. A partir da análise de Crocco et al. (2003), do ponto de vista dos bancos, a preferência pela liquidez afetará negativamente a sua intenção de emprestar a uma região caso possua um alto nível de incerteza. Vale destacar que essa preferência pela liquidez pode ser influenciada pela expectativa de desenvolvimento regional, instabilidade da região e

\footnotetext{
${ }_{1}$ Pesquisadora vinculada a Faculdade de Economia, e-mail: nathalia.lemos@icsa.ufpa.br..

2 Professora e pesquisadora vinculada a Faculdade de Economia da UFPa, e-mail: camilavogt@ufpa.br.
} 
expectativas quanto à direção das políticas monetárias coordenadas pelo Banco Central (CAVALCANTE et al., 2005).

A partir disso, é com intuito de destacar a importância da preferência pela liquidez na oferta de crédito que esse trabalho se apresenta, reforçando alguns pontos baseados na teoria pós-keynesiana. É de suma importância entender e destacar os pontos de impacto na oferta de crédito regional, e aqui o foco é na preferência pela liquidez, visto que esta está relacionada a diversos levantamentos de interesse, como a questão da taxa de juros, da moeda, da incerteza, da concentração regional e do impacto bancário.

A ideia de levantar esse estudo para o Pará, a partir do que foi abordado por Cavalcante et al (2005) para o Brasil, e por Monte e Viana (2014) para o Espírito Santo, parte do princípio de que esse estado, apesar da vasta riqueza, apresenta baixos indicadores de desenvolvimento. Considerando o IDH (Índice de Desenvolvimento Humano) de 2010, o Pará encontra-se em $24^{\circ}$ posição, com 0,646. Com base nisso é que esse trabalho se estrutura, visando analisar a participação bancária nos municípios do Pará (PNUD, 2010).

Toda essa base e levantamento visa condicionar os fatores de concentração de crédito bancário em áreas mais desenvolvidas e destacar os seus impactos para a economia regional em destaque. Para tanto, este trabalho está estruturado em três seções, além desta breve introdução e das considerações finais. Na primeira, faz-se uma análise a partir do arcabouço teórico visando destacar os principais pontos de interesse ao objetivo do estudo. Na segunda seção é abordada a metodologia do trabalho. Por fim, na terceira seção encontra-se a discussão dos resultados obtidos.

\section{PREFERÊNCIA PELA LIQUIDEZ E O COMPORTAMENTO DOS BANCOS NA OFERTA DE CRÉDITO}

Keynes, na Teoria Geral, afirmou que "a taxa monetária de juros é uma porcentagem de excedentes de uma soma de dinheiro contratada para entrega futura" (KEYNES, pg. 219, 1996), ou seja, é o que se ganha a mais ao adquirir um recurso com entrega futura e não imediata, considerando um mercado com apenas duas classes de ativos: moeda e títulos. Com essa ideia, é possível estabelecer que cada grupo de bens deveria ter uma taxa análoga à da taxa monetária de juros, isto é, cada categoria de bens teria sua "própria" taxa de juros.

Keynes prossegue fazendo uma análise de quais seriam as taxas de juros de alguns bens em um determinado período. Ele afirma que existem três atributos que os bens possuem: 1) Existem bens que geram rendimentos; 2) Existem bens que sofrem depreciação, gerando um 
custo de manutenção; 3) Por fim, há bens que a preferência por os ter em mãos gera uma segurança, e para que estes deixem de usufruir da comodidade é oferecido um prêmio de liquidez. Existem bens que possuem rendimentos mais elevados que o custo de manutenção, e um prêmio de liquidez insignificante, como uma máquina; existem aqueles em que os estoques de bens líquidos possuem o custo de manutenção mais elevado que o rendimento, visto que são mercadorias paradas, e um prêmio de liquidez também insignificante; e existem os bens que não possuem rendimento e nem custo de manutenção significante, mas possuem alto prêmio de liquidez, como a moeda (KEYNES, 1936).

A moeda é uma forma de riqueza e a taxa de juros é o preço que determina a escolha entre reter ou não essa riqueza. Nesse modelo, abrir mão da moeda para obter títulos representa abrir mão de uma maior liquidez, que é recompensada pelo preço oferecido, isto é, pelos juros pagos aos títulos. Em relação à demanda de moeda ou preferência pela liquidez, Keynes incorporou a incerteza acerca das variações futuras na taxa de juros. Com isso, a moeda deixou de ser vista como um elemento de intermediação de trocas, que não afetava variáveis como a taxa de juros e o nível de emprego (MINSKY, 1986).

Em uma economia monetária, os agentes retêm moeda por três motivos: transação, precaução e especulação. 0 motivo de transação diz respeito à necessidade de manter recursos líquidos para garantir a transição entre recebimentos e pagamentos. Já o motivo de precaução está relacionado com a necessidade de ter recursos frente a despesas não previstas e urgentes. Por fim, o motivo especulação está relacionado com os ganhos excepcionais, na obtenção de títulos, de acordo com a taxa de juros. Com isso, é possível observar que os motivos de precaução e especulação são definidos conforme as incertezas quanto ao futuro (LOPES \& ROSSETI, 1992).

Na Teoria Geral, Keynes (1936) elaborou a teoria da preferência pela liquidez onde a taxa de juros é uma recompensa por abrir mão dessa liquidez, ou seja, da segurança em ter maior controle sobre a moeda. Em relação aos bancos, ela é expressa como uma cesta específica de ativos escolhidos por eles, de acordo com os diferentes graus de liquidez associados aos vários ativos com possibilidade de posse. Com isso, a partir da escolha de ativos a serem adquiridos, respeitando o trade-off entre liquidez e rentabilidade, ocorre a expansão ou contração da oferta de moeda (FRAGA, 2009).

A partir disso, Kaldor (1960) foi um dos primeiros economistas a desenvolver o modelo apresentado por Keynes. Para Kaldor o resultado de uma "preferência pela liquidez" pode ser explicado como consequência de atividades especulativas. Ele analisa a teoria de Keynes de que a taxa de juros de longo prazo é determinada pela preferência pela liquidez, chegando a resultados próximos, mas por caminhos distintos. $O$ autor afirma que existe uma insensibilidade da taxa de 
juros de longo prazo a influências externas (oferta e demanda de poupança) e que isso não se deve a um prêmio de liquidez vinculado ao dinheiro no curto prazo.

Ele prossegue afirmando que a taxa de longo prazo não é igual ao prêmio de liquidez Supõe que as expectativas são certas, de modo que esse prêmio é ausente, pois este representa apenas a distinção entre a taxa de longo prazo e a média esperada das taxas de curto prazo. Kaldor conclui que apenas mudanças no nível de renda, e, por consequência, mudanças no nível de dinheiro é o que afeta a taxa de juros de longo prazo de alguma forma, pois essas mudanças reagem sobre a taxa de curto prazo, que afeta as expectativas de juros futuros (KALDOR, 1939).

Além dele, Joan Robinson desenvolveu o conceito de preferência pela liquidez em uma teoria de precificação de ativos. Para isso, ela elencou as principais desvantagens presentes em ativos não monetários, onde os preços desses ativos refletem a análise dessas desvantagens por detentores de riqueza (moeda). Davidson foi outro autor de destaque, onde buscou diversificar 0 modelo de Kaldor e formular uma teoria keynesiana que se apoia no modelo de precificação de ativos (CARVALHO, 1996).

Assim a partir da perspectiva pós-keynesiana, bancos são vistos como uma firma que possui a capacidade de criar crédito através da criação de moeda bancária. Ou seja, a partir da escolha entre liquidez e rentabilidade, ocasionando em uma expansão ou contração da oferta de moeda, gera-se uma expansão ou contração da oferta de crédito bancário.

Os bancos são uma empresa dinâmica e inovadora com fins lucrativos. Empresários de bancos procuram ativamente construir suas fortunas ajustando seus ativos e passivos, ou seja, suas linhas de negócios, para aproveitar as oportunidades de lucro. $O$ ativismo desse banqueiro afeta não apenas o volume e a distribuição das finanças, mas também o comportamento cíclico dos preços, receitas e emprego. Com isso, eles tomam suas decisões de portfólio levando em consideração as suas expectativas, o que delimita a sua preferência em manter ativos líquidos. $A$ partir disso, a oferta de crédito bancário "depende fundamentalmente de suas expectativas quanto à viabilidade dos empréstimos, ou seja, da capacidade do tomador de auferir receitas futuras para cumprir seus compromissos financeiros" (PAULA, 2006). Como mostra Fraga:

"Ao avaliar o portfólio de um banco, percebe-se que, quando suas expectativas forem mais otimistas, os bancos valorizam mais a rentabilidade em troca de liquidez, elevando prazos e submetendo-se a maiores riscos quanto a seus ativos" (FRAGA, 2009, pg. 160)

Diante disso, a firma bancária necessita de uma administração do seu balanço patrimonial, para que no lado do ativo possa escolher a cesta de ativos que irá reter e no lado do passivo possa administrar suas obrigações, inovar financeiramente e captar fundos para expandir seus ativos. Diante disso, de acordo com Carvalho (1993), os bancos devem criar estratégias de operação para conciliar a busca da maximização do lucro com sua escala de preferência pela liquidez. 
A maior dificuldade enfrentada pelos bancos é em relação à escolha da sua cesta de ativos. Keynes demonstrou que cada grupo de ativos possui sua própria taxa de juros. A partir disso, ele apresentou que a preferência pela liquidez é refletida de acordo com a escolha entre os retornos monetários e o prêmio pela liquidez da moeda. Assim, em Treatise on Money (1971), ele divide os grupos de ativos em três categorias: 1) letras de câmbio e call loans; 2) investimentos; 3) e empréstimos (PAULA, 2006).

Em relação à rentabilidade dos ativos, de modo geral, os empréstimos são mais lucrativos que os investimentos, e estes são mais lucrativos que as letras de câmbio e call loans. Já em relação à liquidez, de modo geral, as letras de câmbio e call loans são mais líquidos que os investimentos, e estes são mais líquidos que os empréstimos (PAULA, 2006). A partir disso, é com a escolha de que ativos comprar e que obrigações emitir que gera a expansão ou contração da oferta de moeda, ou seja, como mencionado anteriormente, a oferta de moeda depende da preferência pela liquidez, e esta depende das expectativas dos bancos.

Essas expectativas dos bancos sob condições de incerteza possuem a função fundamental na determinação da composição dos ativos dos bancos. Visto que, estes preferem aplicações mais líquidas e, consequentemente, menos rentáveis, diante da incerteza quanto ao futuro. De acordo com Paula (2006), "Quando suas expectativas são otimistas, os bancos privilegiarão rentabilidade à liquidez, procurando elevar prazos e submeter-se a maiores riscos com relação a seus ativos, [...], o que resulta no crescimento da participação dos adiantamentos e de ativos de maior risco na composição de sua estrutura ativa, como os empréstimos de mais longo prazo". Ao mesmo tempo, os bancos podem adotar métodos de administração do seu passivo para aumentar suas operações ativas e conquistar mais rentabilidade. Essas ações dos bancos proporcionam o aumento da oferta de crédito aos clientes, sendo que, quando as expectativas são pessimistas ocorre o processo contrário, destacando a contração da oferta de crédito. "Mais especificamente, procurarão reduzir o prazo médio de seus ativos e adotar uma posição mais líquida, através da manutenção de reservas excedentes ou compra de ativos de grande liquidez, como os papéis do governo, diminuindo, em contrapartida, a participação de adiantamentos no total do ativo e privilegiando as aplicações em ativos mais líquidos e de menor risco" (PAULA, 2006, pg. 342).

\subsection{PREFERÊNCIA PELA LIQUIDEZ E O DESENVOLVIMENTO REGIONAL}


Dow $(1982,1987,1990)$ apresentou as principais ferramentas necessárias para analisar o ideal pós-keynesiano de não neutralidade da moeda, ou seja, a sua influência sobre as variáveis reais na economia. $O$ modelo desenvolvido por ela visa analisar a relação entre moeda e produção, e procura observar qual seria a reação desses elementos em economias diversas.

No modelo pós-keynesiano as noções de tempo, incerteza e moeda são fundamentais para compreender os elementos envolvidos na ideia de não neutralidade da moeda. $O$ tempo utilizado é o histórico, em que não há possibilidade de reversão. A incerteza decorre do tempo histórico e ela não é quantificável, ou seja, para lidar com ela é apenas através do animal spirits ou convenções. E a partir desse ambiente, a liquidez surge para dar flexibilidade aos agentes em um mundo incerto, sendo a moeda sua representante máxima (AMADO, 1997).

A partir disso, Amado (1997) faz um estudo sobre a caracterização de centro e periferia, e seus comportamentos individuais financeiros dos agentes, que estão sujeitos ao fluxo de capitais e mercadorias entre si. $O$ centro seria responsável pelos melhores aspectos inovativos e a periferia deveria se adaptar a esses aspectos de qualquer maneira, ou seja, há prevalência de maior concentração bancária em regiões centrais (mais desenvolvidas).

Em áreas menos desenvolvidas é possível observar uma maior instabilidade, e consequentemente, a incerteza também é maior, o que leva a uma maior preferência pela liquidez dos agentes. Nessas regiões, o setor informal possui uma maior participação na economia como um todo, e com isso, há uma dificuldade da inserção do setor financeiro, visto que há prevalência de indivíduos de baixa renda. Além disso, os bancos também apresentam uma maior preferência pela liquidez nessas regiões, visto que há um alto grau de incerteza, o que interfere na possibilidade de oferta de crédito (AMADO, 1997).

Esse ponto é possível observar a partir do total de crédito disponível entre as regiões do Brasil, em que regiões mais ricas possuem um maior acesso ao crédito, como exemplo pode-se comparar São Paulo e Pará, onde o crédito disponível para São Paulo em 2010 foi de $\mathrm{R} \$ 775.095 .851 .184,00$ e para o Pará foi de $\mathrm{R} \$ 10.713 .090 .305,00$. Em 2017 esses números foram de $\mathrm{R} \$ 1.560 .006 .477 .482,00$ e $\mathrm{R} \$ 24.094 .042 .952,00$ (BACEN, 2021). Com o gráfico 01 pode-se ter uma noção dessa desigualdade, a partir do crédito por habitante.

Gráfico 1: Crédito per capita do Pará, São Paulo e Brasil 


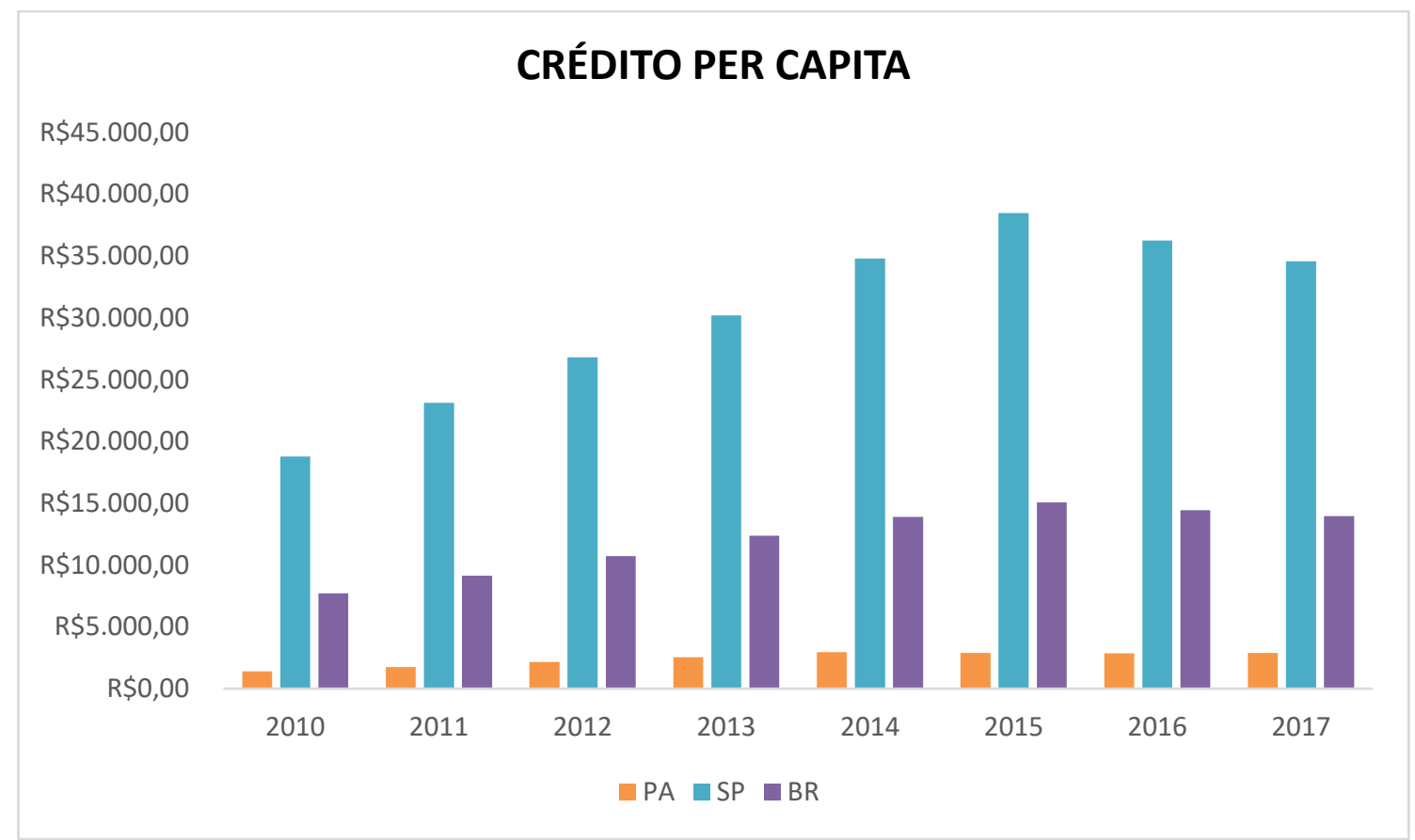

Fonte: Elaboração própria

Por fim, em análise de Crocco et al. (2003), do ponto de vista dos bancos, a preferência pela liquidez afetará negativamente a sua intenção de emprestar a uma região caso possuam expectativas pessimistas sobre a mesma. Essa preferência pela liquidez pode ser influenciada pela expectativa de desenvolvimento regional, instabilidade da região e expectativas quanto à direção das políticas monetárias coordenadas pelo Banco Central (CAVALCANTE et al., 2005).

\section{METODOLOGIA}

\subsection{MODELO UTILIZADO}

Os tipos de dados disponíveis para uma análise aplicada são as séries temporais, os cortes transversais e os painéis. As séries temporais correspondem aos valores observados de uma ou mais variáveis em um período de tempo e os cortes transversais correspondem aos valores observados de uma ou mais variáveis para várias amostras no mesmo período. Já os painéis, a mesma amostra é acompanhada ao longo do tempo, ou seja, os dados em painel abrangem tanto as séries temporais quanto os cortes transversais. De acordo com Hill, Griffiths e Judge (2010), o método geral de dados em painel pode ser representado pela equação 1:

$$
Y_{i t}=\beta_{1 i t}+\beta_{2 i t} \cdot X_{2 i t}+\beta_{3 i t} \cdot X_{3 i t}+\cdots+\beta_{k i t} \cdot X_{k i t}+\mu_{i t}
$$

onde Yit é a variável dependente; Xit são variáveis independentes; $\beta_{1}$ é o intercepto;

$\beta_{2} \ldots \beta_{k}$ são coeficientes parciais de inclinação; $\mu_{i t}$ é termo residual; $i$ representa diferentes indivíduos; e, t é o período de tempo considerado. 
O modelo utilizado neste trabalho serão os dados em painel, em vista da sua melhor técnica de estimação, onde, de acordo com Gujarati (2011), "combinando séries temporais com observações de corte transversal, os dados em painel oferecem 'dados mais informativos, maior variabilidade, menor colinearidade entre variáveis, mais graus de liberdade e mais eficiência'." Esse modelo possui algumas possibilidades de estimação: dados empilhados (pooled data), efeitos fixos (fixed effects) e efeitos aleatórios. Diante disso, visando demonstrar os melhores e mais robustos resultados, neste trabalho foi adotado uma análise do modelo de dados empilhados, como forma de verificar a veracidade dos resultados obtidos:

$$
Y_{i t}=\beta_{1}+\beta_{2} \cdot X_{2 i t}+\beta_{3} \cdot X_{3 i t}+\cdots+\beta_{k} \cdot X_{k i t}+\mu_{i t}
$$

O modelo de dados empilhados pode ser estimado pelo método de MQO, supondo que foram atendidos os pressupostos do modelo clássico (homocedasticidade, normalidade e ausência de correlação entre os resíduos). Caso não tenham sido atendidos, sugere-se usar 0 método de mínimos quadrados generalizados (MQG) ou a ponderação das variáveis, através da atribuição de pesos.

\subsection{VARIÁVEIS}

As variáveis utilizadas nas estimativas estão descritas no quadro 1. Essas variáveis foram escolhidas para suprir o objetivo da pesquisa e para estimação das regressões auxiliares. A análise abrange o período de 2010 a 2017, considerando $143^{3}$ municípios do Pará, contemplando um total de 780 observações. As variáveis CREDITO, DVISTA E DPRAZO foram deflacionadas pelo Índice de Preços ao Consumidor Amplo (IPCA).

Os dados foram coletados no Banco Central do Brasil, por intermédio do programa de Estatística Bancária por Município (ESTBAN), que inclui as contas do ativo e do passivo do balancete dos bancos comerciais e dos bancos múltiplos brasileiros por município (foi utilizado 0 saldo do mês de dezembro de cada ano para representar o saldo anual das operações ativas e passivas dos bancos). Também foram utilizados dados do Instituto Brasileiro de Geografia e Estatística, por meio do Sistema IBGE de Recuperação Automática (SIDRA), que armazena tabelas contendo dados agregados das pesquisas realizadas pelo IBGE. Entre as variáveis disponíveis, foram adotadas a partir do ESTBAN: "operações de crédito", "depósitos à vista", "depósitos de poupança" e "depósitos a prazo"; e a partir do SIDRA: "PIB relativo".

\footnotetext{
30 município Mojui do Campos não foi considerado, visto que obteve sua emancipação de Santarém em 2012, e não foi observado impacto significativo de sua presença nas análises. Além disso, também foram retirados municípios sem dados bancários disponíveis no Estban, a fim de obter resultados mais robustos.
} 
A variável operação de crédito ${ }^{4}$ diz respeito às operações ativas realizadas pelos bancos com o intuito de aplicar seus recursos. Com isso, ela irá representar a proporção de investimento realizado pelos bancos em forma de oferta de crédito nos municípios do Pará. Representando a variável dependente da pesquisa, ou seja, a variável $(Y)$ que será explicada pelas regressões estimadas.

Quadro 1: Variáveis utilizadas para os anos de 2010 a 2017

\begin{tabular}{|l|l|l|l|}
\hline VARIÁVEL & DESCRIÇÃO & FONTE \\
\hline $\begin{array}{l}\text { Operações de } \\
\text { crédito }\end{array}$ & $\begin{array}{l}\text { Representa a atividade de } \\
\text { captação de recursos de } \\
\text { agentes superavitários } \\
\text { e empréstimos a agentes } \\
\text { deficitários }\end{array}$ & CREDITO & ESTBAN \\
(BACEN) & $\begin{array}{l}\text { Operações bancárias passivas } \\
\text { de maior grau de liquidez para o } \\
\text { público tomador de crédito. }\end{array}$ & DVISTA & ESTBAN \\
\hline Depósitos à vista & $\begin{array}{l}\text { Operações bancárias passivas } \\
\text { com maior prazo de maturidade } \\
\text { para resgate. }\end{array}$ & DPRAZO & ESTBAN \\
\hline Depósitos a prazo & $\begin{array}{l}\text { Representa a decisão do público } \\
\text { em geral, de alocação de seus } \\
\text { recursos entre as contas: } \\
\text { depósito à vista, poupança e } \\
\text { depósito a prazo. }\end{array}$ & PLP & (BACEN) \\
\hline $\begin{array}{l}\text { Preferência pela } \\
\text { liquidez do público }\end{array}$ & $\begin{array}{l}\text { Representa a decisão do } \\
\text { sistema bancário em dividir seus } \\
\text { recursos entre ativos de maior e } \\
\text { menor liquidez. Considerando }\end{array}$ & PLB & Elaboração \\
do autor
\end{tabular}

4 Nessa operação de crédito foram utilizados os verbetes, do Estban, 161, 162, 163, 164, 165, 166, 167 e 171. Para fins de mensuração, retirou-se o verbete 169 de crédito imobiliário, visto que este não possui tanto impacto no objetivo deste trabalho. 


\begin{tabular}{|l|l|l|l|}
\hline & $\begin{array}{l}\text { as contas operações de crédito } \\
\text { e depósitos à vista. }\end{array}$ & $\begin{array}{l}\text { através dos } \\
\text { dados do } \\
\text { ESTBAN } \\
\text { (BACEN) }\end{array}$ \\
\hline PIB relativo & $\begin{array}{l}\text { Participação dos bens e serviços } \\
\text { finais produzidos pelos } \\
\text { municípios em relação ao } \\
\text { estado (\%) PIBREL }\end{array}$ & SIDRA (IBGE) \\
\hline Dummy regional & $\begin{array}{l}\text { Visa captar o grau de de } \\
\text { desenvolvimento regional do } \\
\text { estado. Diferenciando as } \\
\text { Regiões Metropolitanas do Pará } \\
\text { das demais regiões. }\end{array}$ & DUMMY \\
\hline
\end{tabular}

Fonte: Elaboração própria

Como visto na literatura, a estrutura de operações bancárias é dividida em ativos e passivos. Entre as contas disponíveis adotadas, "operações de crédito" diz respeito a parte dos ativos bancários que possuem menor liquidez. Já "depósito à vista" e "depósito a prazo" correspondem à parte passiva do sistema bancário. Depósitos a vista corresponde a um processo de maior liquidez para o público, visto que estes depositam em suas contas bancárias e podem resgatar a qualquer momento. Já os depósitos a prazo são aqueles em que existe uma data prefixada para seu resgate, onde o depositante recebe um juro acerca desse depósito.

Com o intuito de representar a preferência pela liquidez do público e do banco, dois índices foram criados, com base no artigo de Cavalcante, Crocco e Jayme (2004), em cima desses depósitos. Acerca da preferência pela liquidez do público, de forma intuitiva ela representa 0 quanto o público deseja reter moeda consigo, para isso, é necessário analisar a proporção entre a operação que garante maior liquidez ao público e o total de depósitos (à vista, a prazo e de poupança), ou seja, a relação entre depósitos à vista e depósitos totais. A partir desse índice, quanto maior o valor dessa relação, maior será a preferência pela liquidez do público.

$$
P L P=\frac{\text { depósitos à vista }}{\text { depósitos totais }}
$$

Sobre a preferência pela liquidez do banco, de acordo com a literatura abordada, ela é maior conforme a maior instabilidade da região em análise, ou seja, ela considera firmemente 0 grau de desenvolvimento da região. Como forma de representar a principal fonte de recursos dos 
bancos, foram utilizados os depósitos a vista, e como forma de representar a disposição bancária de emprestar dinheiro, ou seja, tornar seus ativos menos líquidos, foram utilizadas as operações de crédito. A partir dessa relação, foi criado o índice que representa a preferência pela liquidez dos bancos, logo, quanto maior o seu valor, maior será essa preferência.

$$
P L B=\frac{\text { depósitos à vista }}{\text { operações de crédito }}
$$

Por fim, como exposto pela literatura, com o objetivo de captar os efeitos regionais sobre a oferta de crédito por nível de desenvolvimento, foi criada uma dummy regional que representa as regiões Metropolitanas do Pará (Belém e Santarém). A variável recebe valor um para os municípios que compõem as regiões Metropolitanas (Ananindeua, Belém, Belterra, Benevides, Castanhal, Marituba, Santa Bárbara do Pará, Santa Izabel do Pará e Santarém), e zero para aqueles que não compõem.

\section{RESULTADOS E DISCUSSÃO}

Esta seção destaca as equações estimadas referentes ao objetivo deste trabalho e, por conseguinte, os principais resultados da análise empírica. Nas estimativas, visando uma análise de elasticidade, as variáveis quantitativas foram transformadas em logaritmos. Além disso, os resultados das estimativas estão inseridos nas tabelas 1, 2, 3 e 4.

$O$ intuito deste trabalho é analisar a relação entre a preferência pela liquidez dos bancos e do público como influenciadores da oferta de crédito regional. A hipótese a ser verificada e testada é a de que essas variáveis têm impacto na oferta de crédito, com destaque para o fato de que, de acordo com o referencial teórico, nas áreas menos desenvolvidas há a predominância de uma maior preferência pela liquidez dos bancos, pois há maiores incertezas e dúvidas quanto ao compromisso dessas regiões. Com isso, essa PLB tende a ser maior do que nas regiões mais desenvolvidas, o que possivelmente gera um impacto significativo na oferta de crédito.

Ademais, também foi estimado algumas regressões complementares, utilizando o PIB, depósitos a vista, depósitos a prazo e uma dummy regional. A utilização do PIB visa constatar o efeito do crescimento municipal sobre o crédito através da participação relativa do PIB municipal sobre o estadual. Além disso, também buscou-se compreender como os depósitos citados acima afetam 0 crédito regional. Por fim, a variável dummy foi utilizada com o intuito de destacar o efeito da oferta de crédito por área de desenvolvimento.

As equações foram estimadas em pooling por Mínimos Quadrados Ordinários (MQO) em logaritmos para os municípios $i$ do Pará para o período de 2010 a 2017. Os dados obtidos apresentam heterocedasticidade e não normalidade dos resíduos, o que apesar de resultados 
robustos pode apresentar viés. Os métodos tradicionais não foram capazes de melhorar os dados, havendo apenas uma correção segundo Newey-West através da matriz de covariância, onde há uma ponderação dos resultados obtidos.

As equações estimadas foram:

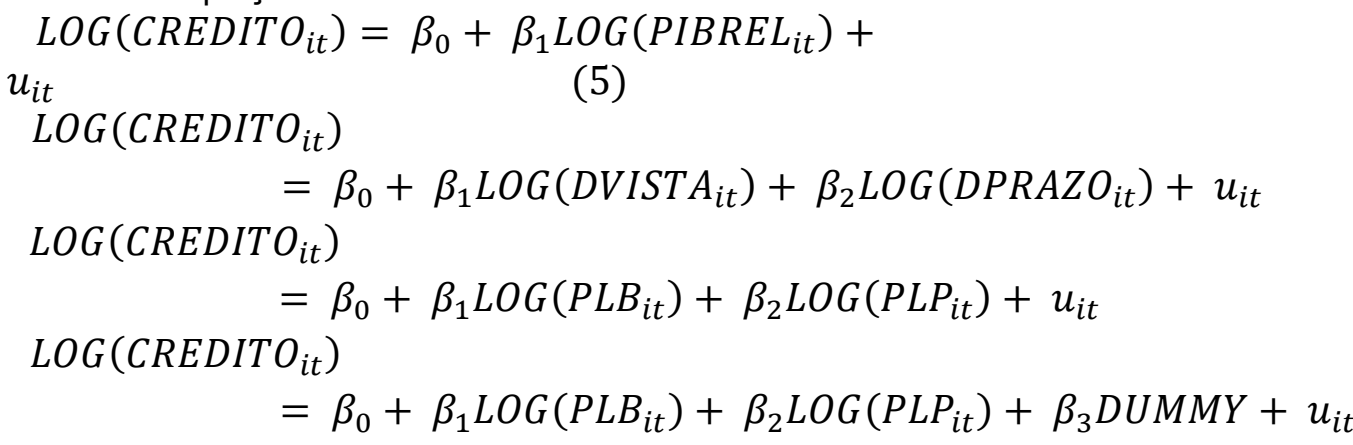

Conforme o resultado exposto na tabela 1, o PIB relativo é estatisticamente significativo a $1 \%$. Ou seja, a variação de $1 \%$ dessa participação relativa do PIB municipal ocasiona em um aumento de $1,22 \%$ nas operações de crédito. 0 sinal positivo condiz com a teoria, significando que em regiões mais desenvolvidas, que consequentemente possuem um PIB maior, há variações positivas entre PIB e crédito.

Tabela 1: Operações de crédito e PIB relativo

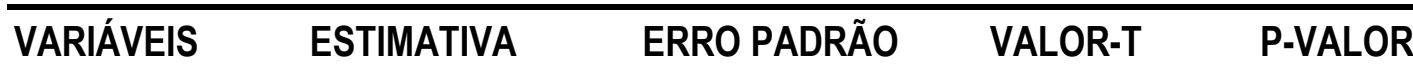

\begin{tabular}{lcccc}
\hline$\beta_{0}$ (Intercepto) & $18,36214^{* * *}$ & 0,055618 & 330,257 & $<2 \mathrm{e}-16$ \\
\hline $\log ($ PIBREL) & $1,229675^{\star \star *}$ & 0,054345 & 22,627 & $<2 \mathrm{e}-16$ \\
\hline $\mathrm{R}^{2}=0,3841$ & $\mathrm{n}=778$ & & \\
\hline
\end{tabular}

$F=485,3$

Obs.: Estimações corrigidas pela heterocedasticidade segundo Newey-West

Fonte: Elaboração própria. Nota: ${ }^{* *}$ Significativo a 1\%; ${ }^{* *}$ Significativo a 5\%; * Significativo a 10\%. Software R.

Nos resultados expostos na tabela 2 é possivel verificar que tanto os depósitos a vista quanto os depósitos a prazo foram estatisticamente significativos a 1\%. Em relação ao peso dos depósitos, é possivel verificar a maior influência dos depósitos a vista do que dos depósitos a prazo, isso porque, 0 aumento de $1 \%$ dos depósitos à vista gera um aumento de $0,47 \%$ no crédito (mantendo dos depósitos a prazo constantes), enquanto a prazo gera um aumento de $0,40 \%$ (mantendo os depósitos a vista constante). 
Esse resultado tem um impacto no longo prazo, visto que os recursos direcionados aos depósitos a prazo representam uma menor preferência pela liquidez do público, o que proporciona ao banco maior possibilidade de estender o prazo de seus ativos. Após a recuperação dos recursos investidos por parte do público, estes recebem o crédito e o redirecionam, no primeiro momento, na forma mais líquida possível, isto é, depositam em sua conta corrente (depósitos a vista), independente da natureza do destino dado a esse crédito.

Tabela 2: Operações de crédito, depósitos à vista e a prazo

\begin{tabular}{lcccc}
\hline VARIÁVEIS & ESTIMATIVA & ERRO PADRÃO & VALOR-T & P-VALOR \\
\hline$\beta_{0}$ (Intercepto) & $3,576278^{* * *}$ & 0,515079 & 6,9432 & $8,15 \mathrm{e}-12$ \\
\hline $\log ($ DVISTA) & $0,479451^{* * *}$ & 0,030362 & 15,7911 & $<2,2 \mathrm{e}-16$ \\
\hline $\log ($ DPRAZO) & $0,403309^{* * *}$ & 0,029722 & 13,5691 & $<2,2 \mathrm{e}-16$ \\
\hline $\mathrm{R}^{2}=0,7536$ & & $\mathrm{n}=770$ & \\
\hline
\end{tabular}

$F=1178$

Obs.: Estimações corrigidas pela heterocedasticidade segundo Newey-West.

Fonte: Elaboração própria. Nota: ${ }^{* *}$ Significativo a 1\%; ${ }^{* *}$ Significativo a 5\%; ${ }^{*}$ Significativo a $10 \%$. Software R.

Em relação aos resultados expostos na tabela 3, tanto a preferência pela liquidez dos bancos, quanto do público, apresentou resultados estatisticamente significativos a 1\%. 0 esperado é de que ambos se relacionem inversamente com o volume de crédito, já que uma maior liquidez, presume uma menor oferta de crédito. Contudo, apesar da PLB apresentar um resultado negativo, a PLP apresentou um resultado positivo. Isso significa que a variação de 1\% na PLB diminui em $1,26 \%$ a oferta de crédito, o que condiz com a teoria abordada, visto que se aumenta a preferência pela liquidez dos bancos há uma diminuição dos seus recursos disponíveis ao público. Já a PLP apresentou um resultado de que se aumenta em 1\%, a disponibilidade de crédito aumenta em $1,59 \%$, representando que existe uma distorção entre a oferta de crédito dos bancos e 0 comportamento dos agentes.

Um estudo feito por Edson Monte e Mirian Viana (2014), acerca da disponibilidade de crédito no Espírito Santo, mostrou que ambas as preferências pela liquidez possuem uma relação negativa com a oferta de crédito, o que condiz com a teoria. Assim como o estudo feito por Anderson Cavalcante, Marco Crocco e Frederico Jayme (2004), sobre a disponibilidade de crédito regional, onde o mesmo resultado foi obtido, de acordo com o arcabouço teórico. Além disso, ambos estudos obtiveram resultado de PLB maior que PLP, o que demonstra que a demanda por 
crédito possui pouco impacto no volume ofertado em uma região. Já para o Pará, os resultados foram contrários a essa ideia, onde a PLP apresentou resultado positivo e maior que a PLB, representando que a demanda por crédito possui um alto impacto na oferta deste.

Tabela 3: Operações de crédito, preferência pela liquidez dos bancos e do público

\begin{tabular}{lcccc}
\hline VARIÁVEIS & ESTIMATIVA & ERRO PADRÃO & VALOR-T & P-VALOR \\
\hline$\beta_{0}($ Intercepto $)$ & $17,54595^{* * *}$ & 0,12466 & 140,7491 & $<2,2 \mathrm{e}-16$ \\
\hline $\log (\mathrm{PLB})$ & $-1,26609^{* * *}$ & 0,12681 & $-9,9845$ & $<2,2 \mathrm{e}-16$ \\
\hline $\log (\mathrm{PLP})$ & $1,59926^{* * *}$ & 0,11514 & 13,8891 & $<2,2 \mathrm{e}-16$ \\
\hline $\mathrm{R}^{2}=0,4011$ & $\mathrm{n}=777$ & & \\
\hline
\end{tabular}

$F=260,2$

Obs.: Estimações corrigidas pela heterocedasticidade segundo Newey-West.

Fonte: Elaboração própria. Nota: ${ }^{* \star}$ Significativo a 1\%; ** Significativo a 5\%; ; Significativo a 10\%. Software R.

Logo, esse resultado pode sinalizar uma falta de coordenação com relação à oferta de crédito, o que é relacionada a baixa disponibilidade ou com políticas de fomento em regiões menos desenvolvidas que naturalmente possuem maior liquidez, como a realizada pelo Banco do Estado do Pará. Em relação à baixa disponibilidade, usando como comparação a oferta de crédito per capita, a partir de uma relação entre Pará, São Paulo e Brasil, foi possível observar a magnitude da discrepância dessa oferta. Em 2010, o crédito por habitante disponível em São Paulo representou $1329,28 \%$ do disponível no Pará e 243,78\% do disponível no Brasil. Já em 2017 , esses números se alteram para $1201,27 \%$ do disponível no Pará e $247,60 \%$ no Brasil. Com isso, é possível constatar a distinta distribuição de crédito per capita no Brasil, que pode explicar a falta de coordenação na oferta de crédito (BACEN, 2021).

Em relação às políticas de fomento, em 2010, 65 municípios não possuíam nenhuma agência bancária (ou, pelo menos, não tem dados disponíveis no Estban). Com as políticas de expansão do Banpará, em 2015, foi possível observar a presença dele em 73 municípios, enquanto em 2010 estava presente em 32 municípios. Já em 2017, o Banpará estava presente em 98 municípios, e aproximadamente 27 municípios ainda não tinham nenhuma agencia bancária. Apesar de alguns municípios ainda não terem esse acesso bancário, foi possível observar a expansão para regiões menos desenvolvidas do Estado ao longo desses sete anos em consideração (BACEN, 2021). 
Além disso, em relação ao crédito, através dos dados do Estban, foi possível verificar que em 2010 o crédito ofertado pelo Banpará correspondia a, aproximadamente, 8,03\% do crédito total do Pará. Já em 2017, essa porcentagem aumentou para, aproximadamente, 15,79\%. Dentre os municípios mais desenvolvidos 5 (Ananindeua, Belém, Marabá, Parauapebas e Tucuruí), 0 crescimento da oferta de crédito do Banpará entre 2010 e 2017 foi de, aproximadamente, 273,6\%. Em contrapartida, para os municípios menos desenvolvidos (Capitão Poço, Concórdia do Pará, Maracanã, Vigia e Viseu), a diferença foi de $348,46 \%$, o que destaca a abrangência desse banco nos municípios menos desenvolvidos no período em análise (BACEN, 2021).

Por fim, a tabela 4 mostra em seus resultados a relação da preferência pela liquidez com a disponibilidade de crédito, ressaltando a diferenciação entre a região Metropolitana e as demais regiões do Pará. É possível observar que todas as variáveis apresentam resultados significativos a $1 \%$. Os resultados mostram que o aumento de $1 \%$ na PLB gera uma diminuição de $1,30 \%$ na disponibilidade de crédito, e que o aumento de $1 \%$ na PLP gera um aumento de 1,63\% no crédito.

Tabela 4: Operações de crédito, preferência pela liquidez dos bancos e do público, e dummy regional

\begin{tabular}{lcccc}
\hline VARIÁVEIS & ESTIMATIVA & ERRO PADRÃO & VALOR-T & P-VALOR \\
\hline$\beta_{0}($ Intercepto) & $17,34883^{* * *}$ & 0,12323 & 140,78 & $<2,2 \mathrm{e}-16$ \\
\hline $\log (\mathrm{PLB})$ & $-1,30217^{* \star *}$ & 0,12079 & $-10,78$ & $<2,2 \mathrm{e}-16$ \\
\hline $\log (\mathrm{PLP})$ & $1,63129^{\star * *}$ & 0,10992 & 14,84 & $<2,2 \mathrm{e}-16$ \\
\hline $\mathrm{DUMMY}$ & $2,45988^{* \star *}$ & 0,25289 & 9,727 & $<2,2 \mathrm{e}-16$ \\
\hline $\mathrm{R}^{2}=0,493$ & $\mathrm{n}=776$ & & \\
\hline $\mathrm{F}=251,5$ & & &
\end{tabular}

Obs.: Estimações corrigidas pela heterocedasticidade segundo Newey-West.

Fonte: Elaboração própria. Nota: ${ }^{* \star \star}$ Significativo a $1 \% ;{ }^{* *}$ Significativo a $5 \%$; ${ }^{*}$ Significativo a $10 \%$. Software R.

A importância da preferência pela liquidez na disponibilidade de crédito é ainda mais forte regionalmente, dado o valor do coeficiente da variável dummy $(2,45988)$. De fato, como exposto pela teoria, a preferência pela liquidez tende a ser maior em regiões menos desenvolvidas, o que permite também 0 argumento teórico de preferência pela liquidez distinta por região. Nos municípios considerados mais desenvolvidos no estado, a oferta de crédito é consideravelmente superior aos demais municípios, dado o menor grau de preferência pela liquidez do público e dos bancos.

\footnotetext{
${ }^{5}$ Considerando o PIB municipal para essa seleção, tendo como base os cinco municípios mais e menos desenvolvidos de 2010.
} 


\section{CONSIDERAÇÕES FINAIS}

A tabela 1 mostrou que existe uma relação positiva entre o PIB e a oferta de crédito, o que representa que aqueles municípios com maior desenvolvimento econômico possuem uma maior capacidade e maior adaptabilidade para ofertar crédito. Em relação às contas dos passivos dos bancos, expressos na tabela 2, foi possível observar que as operações de depósitos à vista e a prazo possuem uma relação positiva com o crédito, reforçando que os depósitos a vista possuem um impacto maior, proporcionando um impacto a longo prazo.

Considerando a preferência pela liquidez, foi possível observar uma particularidade da relação entre a preferência pela liquidez do público e a oferta de crédito, que considera uma falta de coordenação com relação à oferta de crédito. Já a preferência pela liquidez dos bancos apresentou uma relação inversa que condiz com a teoria, visto que quanto maior a preferência pela liquidez dos bancos, menor a oferta de crédito disponibilizada.

Por fim, os resultados considerando uma dummy regional mostraram que as regiões de maior desenvolvimento têm uma maior relação com a oferta de crédito. Isso condiz com a teoria de que regiões mais desenvolvidas proporcionam maiores certezas e segurança, o que incentiva os bancos a disponibilizarem crédito.

A partir disso, é possível entender que as regiões menos desenvolvidas são altamente prejudicadas e limitadas a crescer, visto que a oferta de crédito pode permitir um maior desenvolvimento dessas regiões. Logo, é de fundamental necessidade a formulação de políticas públicas com intuito de oferecer a maior possibilidade de crédito para essas áreas. No caso do Pará, além das possíveis contribuições de bancos públicos federais, também é fundamental 0 incentivo dos demais bancos, como ocorre com o Banco do Estado do Pará, que está presente em diversas áreas menos desenvolvidas fomentando a economia municipal.

\section{REFERÊNCIAS BIBLIOGRÁFICAS}

AMADO, Adriana M. A Questão Regional e o Sistema Financeiro no Brasil: uma interpretação póskeynesiana. Estudos Econômicos: publicação trimestral do Departamento de Economia da Faculdade de Economia, Administração e Contabilidade da Universidade de São Paulo, São Paulo, v. 27, n. 3, p. 417-440, 1997.

BACEN (2021). ESTBAN - Estatística Bancária Mensal por município. Banco Central do Brasil. Disponível em: <https://www4.bcb.gov.br/fis/cosif/estban.asp?frame=1>. Acesso em: 20/05/2021 CARVALHO, Fernando C. Sobre a centralidade da teoria da preferência pela liquidez na macroeconomia pós-keynesiana. Ensaios FEE, v. 17, n. 2, p. 42-77, 1996. 
CAVALCANTE, Anderson; CROCCO, Marco; JAYME Jr., Frederico G. Preferência pela liquidez, sistema bancário e disponibilidade de crédito regional. Texto para Discussão. Belo Horizonte: Cedeplar, 2005.

CROCCO, Marco.; BARRA, Cláudio; CAVALCANTE, Anderson; MUNHOZ, Vanessa. Desenvolvimento econômico, preferência pela liquidez e acesso bancário: um estudo de casos das mesorregiões de Minas Gerais. Revista Análise Econômica, v. 21, n. 40, p. 39-64, 2003.

DAVIDSON, Paul. Money and the real world. 2.ed. London: Macmilian, 1978.

DOW, Sheila C. Financial markets and regional economic development: the Canadian experience. Aldershot, Averbury, 1990 The regional composition of the money multiplier process. Scottish Journal of Political Economy, v. 19, n. 1, 1982.

n. 1, 1987. . The treatment of money in regional economics. Journal of Regional Science, v. 27,

FRAGA, Jefferson S. Uma abordagem pós-keynesiana de preferência pela liquidez: o sistema bancário e a concessão de crédito. RACE - Revista De Administração, Contabilidade E Economia, v. 8, n. 1, p. 155-174, 2009.

GUJARATI, Damodar N.; PORTER, Dawn C. Econometria básica. 5. ed. Porto Alegre: AMGH, p. 924, 2011.

HILL, Carter.; GRIFFITHS, William; JUDGE, George. Econometria. 3. ed. São Paulo: Saraiva, p. 471, 2010.

PNUD - Programa das Nações Unidas para o Desenvolvimento. Índice de Desenvolvimento Humano - IDH. Rio de Janeiro, 2010. Disponível em: $<$ https://cidades.ibge.gov.br/brasil/pa/pesquisa/37/30255?tipo=ranking>. Acesso em: 11/07/2021 KALDOR, Nicholas. Speculation and economic growth. In: - Essays on economic stalibility and growth. New York: Holmer and Maier, 1960.

KEYNES, John M. The general theory of employment, interest and money. 1 ed. Londres: Macmillan, 1936.

A treatise on money. London, Macmillan, v. 1, n. 2, 1971.

MINSKY, Hyman P. Stabilizing an unstable economy. New Haven: Yale University Press, 1986.

MONTE, Edson; VIANA, Mirian. $O$ impacto da preferência pela liquidez na disponibilidade de crédito dos municípios do Espírito Santo. Editora UFPR. Revista de Economia, v. 40, n. 2, p. 129 150, 2014.

OREIRO, José L. Preferência pela liquidez, racionamento de crédito e concentração bancária uma nova Teoria pós-keynesiana da firma bancária. Estudos Econômicos, v. 35, n. 1, p. 101-131, 2005. PAULA, Luiz F. Dinâmica da firma bancária: uma abordagem não-convencional. Revista Brasileira, v.53, n.3, 1999.

\section{Recebido em 20 de janeiro de 2021. \\ Aceito para publicação em 10 de Maio de 2021.}

\section{Resumo}

O presente trabalho visa avaliar o impacto da preferência pela liquidez dos bancos e do público na disponibilidade de crédito nos municípios paraenses. Adotou-se a técnica econométrica de dados em painel empilhado (pooled) e os resultados mostraram que para o período de 2010 a 2017 a preferência pela liquidez dos bancos afetou negativamente a oferta de crédito nos municípios do Pará, o que condiz com a teoria abordada, enquanto a preferência pela liquidez do público apresentou uma relação positiva, representando que existe uma distorção entre a oferta de crédito dos bancos e o comportamento dos agentes. Além disso, utilizando dummy regional, foi 
possível verificar que a disponibilidade de crédito é maior em municípios mais desenvolvidos. Com isso, há evidências significativas de que a preferência pela liquidez é um importante fator na explicação da tendência à concentração regional do crédito nos municípios paraenses.

Palavras-chave: Pará, preferência pela liquidez, crédito, concentração regional

\section{Abstract}

The objective of this work is to evaluate the impact of liquidity preference by banks and the public on the availability of credit in Pará municipalities. The econometric technique of stacked panel data was adopted and the possible results that for the period 2010 to 2017 the preference for bank liquidity negatively affected the supply of credit in the municipalities of Pará, while the preference for public liquidity presents a relationship positive, which raises a point of particularities of the municipalities of Pará. Furthermore, using a regional dummy, it was possible to verify that the availability of credit is greater in more developed municipalities. Thus, there is significant evidence that the preference for liquidity is an important factor in explaining the trend towards regional concentration of credit in Pará municipalities.

Classificação JEL: E5; R11; R15 